\title{
Changing pattern of rheumatic fever in a paediatric ward : then and now
}

\author{
K S H de Silva ${ }^{1}$ \\ Sri Lanka Journal of Child Health 2010; 39: 17-21
}

(Key words: Sri Lanka, children, rheumatic fever, rheumatic heart disease)

\begin{abstract}
Objectives: To describe the socio-demographic and clinical features of children with primary episode of rheumatic fever (RF) during two periods of time and to attempt a comparison of the clinical features with previously published data from the same ward at Lady Ridgeway Hospital (LRH), Colombo.
\end{abstract}

Method: Children admitted to University Paediatric Unit with the primary episode of RF based on the revised Jones criteria, were studied. Sociodemographic and clinical features were recorded prospectively from August 1994 to August 1999 and compared with data collected retrospectively from January 2004 to December 2008. Respecting the limitations, an attempt was made to compare this data with previously published data from the same ward during a period of ten years from 1966, when the primary episode of RF was diagnosed based on the modified Jones criteria.

Results: There were 91 children from 1994 to 1999 and $52(57 \%)$ were boys. Majority were $>5$ years and from families with a monthly income $<$ Rs. $10,000.00$ but $56(62 \%)$ of their mothers were educated up to Grade 10. Migratory polyarthritis was seen in $56(62 \%)$ and $58(64 \%)$ had a significant murmur on admission. Echocardiography was done on 87 and 24 (28\%) had evidence of rheumatic heart disease (RHD). There were 29 (17 boys) during the 4 years from January 2004. Echocardiography was done on all the patients and 8 (28\%) had RHD. During 1966 1976, RHD diagnosed on clinical features, was reported in $42 \%$ of 158 children ( 92 girls). Chorea has progressively increased through the years, with girls being more commonly affected.

Conclusions: Childhood RF has declined in Sri Lanka. Disease pattern has also changed with more boys being affected but chorea continues to manifest more commonly in girls. RHD continues to be an important manifestation.

${ }^{1}$ Senior Lecturer in Paediatrics, Faculty of Medicine, University of Colombo

(Revised version received on 23 April 2009. Accepted on 26 June 2009)

\section{Introduction}

Rheumatic fever (RF) has been an important cause of morbidity in Sri Lankan children. Stanley de Silva reported a series of 107 patients admitted to a ward at the Lady Ridgeway Hospital (LRH) during $1953-1957^{1}$ and Priyani Soysa et al in their report ${ }^{2}$ had 328 children admitted to the University Paediatric Unit in the same hospital over 10 years from 1966. In the recent past, the number of children admitted with rheumatic fever has declined.

\section{Objectives}

This study was done to describe the sociodemographic and clinical features of children with the primary episode of rheumatic fever (RF) admitted to a ward at LRH during two periods of time, and to attempt a comparison between the disease manifestations of the recent study with previously published data regarding the primary episode of RF, from the same ward.

\section{Method}

Children admitted to the University Paediatric Unit with RF conforming to the revised Jones criteria ${ }^{3}$ from August 1994 to August 1999 were prospectively studied. The socio-demographic and clinical features were recorded and the children were examined by the investigator. Throat swabs were obtained on the day of admission and were cultured on blood agar. Beta haemolytic streptococci were isolated and subsequently identified as group A by using the Bacitracin test and Lancefield grouping ${ }^{4,5,6}$. Echocardiography was done at the Cardiology Unit of the National Hospital, Colombo as LRH did not have a cardiology unit at that time, and thus the investigation was done by different cardiologists over the years.

Hospital records of children admitted to the same ward with RF from January 2004 to December 2008, diagnosed according to the revised Jones criteria, were perused retrospectively and the data during these two periods of study were compared. A comparison was attempted with data published from the same ward from 1966 to 1976 subject to the limitations that the diagnosis of the primary episode of RF was based on the modified Jones 
criteria and RHD was a clinical diagnosis based on the presence of a cardiac murmur or evidence of cardiac failure or presence of pericarditis ${ }^{2}$. The modified (1956) and revised Jones criteria $(1965 / 1984)$ are similar except that evidence of a recent streptococcal infection is an essential criterion in the latter definition whereas it was a minor criterion in the former ${ }^{7}$. The Ethical Review Committee of the Faculty of Medicine, Colombo approved the study.

\section{Results}

There were 96 children with various manifestations of RF admitted during the 5 years from 1994 to 1999. A significant seasonal variation in the admissions was not observed. Majority (91, 95\%) were admitted with the primary episode, while 4 children had been previously diagnosed as having rheumatic heart disease (RHD) and one as having chorea. Twelve children gave a previous history of joint symptoms which had not been investigated.

Following is a description of the 91 children with the primary episode of RF. Fifty two $(57 \%)$ were boys. Eighty four $(92 \%)$ were more than 5 years of age. Seventy eight children (86\%) came from families with a monthly income less than Rs. $10,000.00$ but $56(62 \%)$ of their mothers were educated up to Grade 10 (Table 1).

Table 1

Socio-demographic features of the study populations

\begin{tabular}{|c|c|c|}
\hline & $\begin{array}{c}1994-1999 \\
n=91\end{array}$ & $\begin{array}{c}2004-2008 \\
n=29\end{array}$ \\
\hline Boys & 52 & 17 \\
\hline Girls & 39 & 12 \\
\hline Age (years) $<5$ & 07 & 02 \\
\hline $5-10$ & 57 & 18 \\
\hline$>10$ & 27 & 09 \\
\hline Monthly family income: (Rs) & & NA \\
\hline$<5000.00$ & 43 & - \\
\hline $5-10,000.00$ & 35 & - \\
\hline $10-20,000.00$ & 13 & - \\
\hline$>20,000.00$ & 00 & - \\
\hline Mothers' education (Grade) & & NA \\
\hline No formal education & 05 & - \\
\hline$<5$ & 15 & - \\
\hline $5-10$ & 41 & - \\
\hline O’Level & 18 & - \\
\hline A'Level and higher & 12 & - \\
\hline
\end{tabular}

Fifty six $(62 \%)$ presented with migratory polyarthritis while $58(64 \%)$ had a significant murmur at presentation. Two children were in heart failure while 6 had clinical and echocardiographic evidence of infective endocarditis. Thirteen (08 girls) presented with chorea (Table 2). One child with RHD and infective endocarditis subsequently died after several admissions, 3 years after initial presentation.

Table 2 Clinical features of the primary episode of RF during the two periods of study

\begin{tabular}{lcc}
\hline & $\begin{array}{c}\mathbf{1 9 9 4} \mathbf{1 9 9 9} \\
\mathbf{n = 9 1}\end{array}$ & $\begin{array}{c}\mathbf{2 0 0 4} \mathbf{2 0 0 8} \\
\mathbf{n = 2 9}\end{array}$ \\
\hline Migratory polyarthritis & 56 & 20 \\
Migratory polyarthralgia & 16 & 06 \\
Presence of a murmur & 48 & 08 \\
Chorea & 03 & 05 \\
Chorea + murmur & 10 & 05 \\
Infective endocarditis & 06 & 00 \\
Heart failure & 02 & 02 \\
Subcutaneous nodules & 01 & 00 \\
\hline Total number with a murmur & $\mathbf{5 8}$ & $\mathbf{1 3}$ \\
\hline
\end{tabular}


Investigations performed are given in Table 3. An ESR more than $50 \mathrm{~mm}$ in the first hour was seen in 75 children $(82 \%)$ while a significantly elevated ASOT $\geq 400$ Todd units $/ \mathrm{ml}$ was observed in 74
$(81 \%)$. Throat swabs were obtained from 84 children and group A $\beta$ haemolytic streptococci were isolated from $18(21 \%)$ swabs.

Table 3

Investigations performed during the two periods of study

\begin{tabular}{|c|c|c|}
\hline & $\begin{array}{c}1994-1999 \\
n=91\end{array}$ & $\begin{array}{c}2004-2008 \\
n=29\end{array}$ \\
\hline \multicolumn{3}{|l|}{ ESR ( $\mathrm{mm}$ in the first hour) } \\
\hline$<30$ & 09 & 04 \\
\hline $31-50$ & 07 & 07 \\
\hline $51-100$ & 53 & 14 \\
\hline$>100$ & 22 & 04 \\
\hline \multicolumn{3}{|l|}{ ASOT $^{*}$ (Todd units $\left./ \mathrm{ml}\right)$} \\
\hline$\leq 200$ & 16 & 07 \\
\hline$\geq 400$ & 74 & 17 \\
\hline Not done/not available & 01 & 05 \\
\hline \multicolumn{3}{|c|}{$\begin{array}{l}\text { Throat swab culture for group } A \beta \\
\text { haemolytic streptococcus }\end{array}$} \\
\hline Group A +ve & 18 & - \\
\hline Group A -ve / No growth & 54 & - \\
\hline No report & 12 & - \\
\hline Not done & 07 & 29 \\
\hline
\end{tabular}

* Initial or subsequent

Echocardiography was performed during the hospital stay on 87 children. Twenty three of the 58 with a murmur had evidence of RHD and one child without a murmur had similar findings (Table 4).
Therefore in this series, 24 out of $87(28 \%)$ with the primary episode of RF had echocardiographic evidence of RHD.

Table 4

Echocardiographic evaluation of patients with primary episode of RF during the two periods of study

\begin{tabular}{lcc}
\hline & $\begin{array}{c}\mathbf{1 9 9 4} \mathbf{- 1 9 9 9} \\
\mathbf{n = 9 1}\end{array}$ & $\begin{array}{c}\mathbf{2 0 0 4}-\mathbf{2 0 0 8} \\
\mathbf{n}=\mathbf{2 9}\end{array}$ \\
\hline $\begin{array}{l}\text { Number on whom echocardiography was } \\
\text { done }\end{array}$ & 87 & 29 \\
\hline Number with a murmur & 58 & 13 \\
\hline Rheumatic heart disease & 23 & 06 \\
Mitral valve prolapse & 28 & 06 \\
Normal heart & 07 & 01 \\
\hline Number without a murmur & 33 & 16 \\
\hline Rheumatic heart disease & 01 & 02 \\
Mitral valve prolapse & 05 & 00 \\
Normal heart & 23 & 14 \\
Echocardiography not done & 04 & 00 \\
\hline Percentage with RHD & $\mathbf{2 8 \%}$ & $\mathbf{2 8 \%}$ \\
\hline
\end{tabular}

There were 31 children admitted to the same ward with RF during the 4 year period of retrospective evaluation, from January 2004 to December 2008. This was the initial presentation in 29 (17 boys). Twenty seven $(93 \%)$ were $>5$ years of age. Thirteen (45\%) had a significant murmur and 8 $(28 \%)$, two of whom did not have a murmur, had evidence of RHD on echocardiography. Details of the family income and education level of mothers could not be obtained from the records. Throat swabs had not been done on any of the patients. Tables 1-4 are a comparison of the socio- demographic features, clinical and echocardiography findings of the primary episode of RF during the 2 periods of study.

\section{Discussion}

$\mathrm{RF}$ is still rampant in developing countries, whereas the incidence is negligible in developed countries $^{7}$ apart from the resurgence reported from USA in $1987^{8,9}$. Improvement of housing and living standards is implicated as the reason for the very low incidence of RF in the more affluent countries 
of the world. According to the Demographic and Health Surveys 2000, 1993, 1987 of the Department of Census and Statistics, a survey of 8918 and 8169 houses in 1993 and 2000 respectively, has shown a possible improvement in our living standards. This is reflected by a reduction in the 'Mean household size' of 4.5 in 2000 from 4.7 in 1993. The 'Percent of one member households' has also increased to 3.7 in 2000 from 3.3 in 1993.

Although no definite reason has been implicated, the number of children presenting with the primary episode of RF has decreased over the years. Stanley de Silva, one of the first three paediatricians appointed to the Lady Ridgeway Hospital ${ }^{10}$, had reported 107 patients admitted to his ward from 1953 - 1957: approximately 21 patients/year ${ }^{1}$, and the University Paediatric Unit had 328 patients admitted with RF from 1966 - 1976: approximately 33 patients/year ${ }^{2}$. At the turn of the century in the same ward, the present report documents a progressive decline in the number of patients presenting with the primary episode of RF from 91 during $1994-1999$ ( 18/year) to 29 for 4 years ( 7/year) from January 2004 to December 2008, based on similar diagnostic criteria.

The disease pattern of the primary episode has also changed over the years. During 1953 - 1957 RHD (probably diagnosed clinically) had been seen in $31 \%^{1}$ in one ward (34 of 107). Although 328 patients had been admitted to the University Paediatric Unit during 10 years from 1966, data was available only on 158 patients. RHD was seen in $42 \%$ (66 of 158) during the initial attack ${ }^{2}$. This has fortunately decreased to $28 \%$ during both study periods (Table 5).

Table 5

Sex distribution of RHD and chorea in the primary episode of RF* observed in the same ward* over time

\begin{tabular}{|c|c|c|c|}
\hline & $\begin{array}{c}1966-1976 \\
n=158^{\circ}\end{array}$ & $\begin{array}{c}1994-1999 \\
n=91\end{array}$ & $\begin{array}{c}2004-2008 \\
n=29\end{array}$ \\
\hline Boys : Girls & $\begin{array}{l}66: 92 \\
1: 1.39\end{array}$ & $\begin{array}{l}52: 39 \\
1: 0.75\end{array}$ & $\begin{array}{l}17: 12 \\
1: 0.71\end{array}$ \\
\hline RHD (\%) & $66(42)$ & $24(28) \quad \mathrm{n}=87^{\star}$ & $8(28) \quad n=29^{\circ}$ \\
\hline Boys : Girls & $1: 1$ & $13: 11(1: 0.85)$ & $7: 1(1: 0.14)$ \\
\hline $\begin{array}{l}\text { Chorea (\%) } \\
\text { Boys : Girls }\end{array}$ & $\begin{array}{c}15(9.5) \\
1: 14\end{array}$ & $\begin{array}{c}13(14) \\
5: 8(1: 1.6)\end{array}$ & $\begin{array}{c}7(24) \\
2: 5(1: 2.5)\end{array}$ \\
\hline
\end{tabular}

* Diagnostic criteria: 1966 - $1976 \rightarrow$ modified Jones criteria,

* University Paediatric Unit

$$
1994-1999 \text { and } 2004-2008 \rightarrow \text { revised Jones criteria }
$$

- Number on whom follow up data is available (Total number of admissions = 328)

- Number on whom echocardiography was performed

Subcutaneous nodules had been extremely rare in the 1950s and along with erythema marginatum had not been seen during 1966 - 1976. Only one child had subcutaneous nodules associated with carditis in the present series. Chorea was reported as very uncommon in the fifties, but was seen in 15 children $(9.5 \%)$, more than ten years later ${ }^{2}$, while a progressive increase is observed in the present study. The attempted 'comparison' of the clinical manifestations of the initial attack of RF in children admitted to the same unit is given in Table 5 . Initially girls had been predominantly affected whereas now RF and RHD appear to be commoner in boys. The female preponderance of chorea has persisted over the years. This present observed trend of a decline in the occurrence of RF augurs well for our country. But RHD is still an important cause of morbidity in Sri Lankan children.

\section{Acknowledgements}

I wish to thank Prof. S.P. Lamabadusuriya under whose care these children were admitted and Drs. Kumarangie Vithanage and S.T. Samarawickrema for obtaining data from the bed head tickets for the retrospective analysis.

\section{References}

1. de Silva S. Incidence of rheumatic fever in Ceylon. Archives of Disease in Childhood 1959; 34:247-9.

2. Soysa PE, de Silva DGH, Ariyananda PL, de Silva DDS. The pattern of rheumatic fever in a paediatric unit in Colombo. The Ceylon Medical Journal 1980; 25:26-8. 
3. Rheumatic fever and rheumatic heart disease. Report of a WHO Study Group. WHO Technical Report Series 1988; 764:17-21.

4. de Silva KSH, Gunatunga MW, Perera AJ, Jayamaha DJMNR. Can Group A beta haemolytic streptococcal sore throats be identified clinically? The Ceylon Medical Journal 1998; 43(4):196-9.

5. Barrow GI, Feltham RKA, editors. Cowen and Steels Manual of Medical Bacteria. $3^{\text {rd }}$ ed. 1993; Cambridge University Press.

6. Peter G, Smith AL. Group A streptococcal infections of the skin and pharynx (Part 1). New England Journal of Medicine 1977; 297:311-7.
7. Rheumatic fever and rheumatic heart disease. Report of WHO Expert Consultation 2001. WHO Technical Report Series 2004; 923:3-12.

8. Veasy LG, Wiedmeier SE, Orsmond GS. et al. Resurgence of acute rheumatic fever in the intermountain area of the United States. The New England Journal of Medicine 1987; 316(8):421-7.

9. Hosier DM, Craenen JM, Teske DW, Wheller JJ. Resurgence of acute rheumatic fever. American Journal of Diseases of Children 1987; 141:730-3.

10. Senanayake MP. Paediatrics and Childcare in Sri Lanka: The Past Unfolded. $1^{\text {st }}$ ed. Colombo: Vijitha Yapa Publications 2007. 

